\title{
INTRALUMINAL ULTRASONIC PALPATION IMAGING TECHNIQUE REVISITED FOR ANISOTROPIC CHARACTERIZATION OF HEALTHY AND ATHEROSCLEROTIC CORONARY ARTERIES: A FEASIBILITY STUDY
}

\author{
Armida Gómez,* Antoine Tacheau, ${ }^{*}$ Gérard Finet, ${ }^{\dagger}$ Manuel Lagache, ${ }^{\ddagger}$, Jean-Louis Martiel, ${ }^{*}$ \\ Simon Le Floc’h, ${ }^{\top}$ Saami K. Yazdani, ${ }^{\|}$Alex Elias-Zuñiga, ${ }^{\#}$ Roderic I. Pettigrew, ${ }^{* *}$ \\ Guy Cloutier, ${ }^{\dagger \dagger}$ and JACQues OHAYon $*, \S$ \\ * Laboratory TIMC-IMAG/DyCTiM, UGA, CNRS UMR 5525, Grenoble, France; ${ }^{\dagger}$ Department of Hemodynamics and \\ Interventional Cardiology, Hospices Civils de Lyon and Claude Bernard University Lyon1, INSERM Unit 886, Lyon, France; \\ ${ }^{\ddagger}$ Laboratory SYMME, SYMME, University Savoie Mont-Blanc, France, ${ }^{\S}$ Polytech Annecy-Chambéry, University Savoie Mont-
Blanc, Le Bourget du Lac, France; ${ }^{2}$ Laboratory LMGC, CNRS UMR 5508 , University of Montpellier II, Montpellier, France; \\ " Department of Mechanical Engineering, University of South Alabama, Mobile, Alabama, USA; ${ }^{*}$ Department of Mechanical \\ Department of Mechanical Engineering, University of South Alabama, Mobile, Alabama, USA; ${ }^{*}$ Department of Mechanical
Engineering Instituto Tecnologico y de Estudios Superiores de Monterrey, Campus Monterrey, Monterrey, Mexico; ** Texas A\&M \\ University Engineering Health (EnHealth), Houston, Texas, USA; and ${ }^{\dagger \dagger}$ Laboratory of Biorheology and Medical Ultrasonics, \\ University of Montreal Hospital Research Center (CRCHUM), Montréal, Québec, Canada
}

\begin{abstract}
Accurate mechanical characterization of coronary atherosclerotic lesions remains essential for the in vivo detection of vulnerable plaques. Using intravascular ultrasound strain measurements and based on the mechanical response of a circular and concentric vascular model, E. I. Céspedes, C. L. de Korte and A. F. van der Steen developed an elasticity-palpography technique in 2000 to estimate the apparent stress-strain modulus palpogram of the thick subendoluminal arterial wall layer. More recently, this approach was improved by our group to consider the real anatomic shape of the vulnerable plaque. Even though these two studies highlighted original and promising approaches for improving the detection of vulnerable plaques, they did not overcome a main limitation related to the anisotropic mechanical behavior of the vascular tissue. The present study was therefore designed to extend these previous approaches by considering the orthotropic mechanical properties of the arterial wall and lesion constituents. Based on the continuum mechanics theory prescribing the strain field, an elastic anisotropy index was defined. This new anisotropic elasticity-palpography technique was successfully applied to characterize ten coronary plaque and one healthy vessel geometries of patients imaged in vivo with intravascular ultrasound. The results revealed that the anisotropy index-palpograms were estimated with a good accuracy (with a mean relative error of $26.8 \pm \mathbf{4 8 . 8 \%}$ ) compared with ground true solutions. (E-mail: jacques. ohayon@univ-grenoble-alpes.fr)
\end{abstract}

Key Words: Atherosclerosis, Vulnerable plaques, Biomechanics, Orthotropic material, Coronary disease, Plaque detection, Linear incremental elasticity, Inverse problem.

\section{INTRODUCTION}

Morphologic and mechanical characterization of coronary atherosclerotic lesions remains an essential step for the diagnosis of rupture-prone plaques and subsequent thrombosis (Alsheikh-Ali et al. 2010; Arbab-Zadeh et al. 2012; Benjamin et al. 2017; Fleg et al. 2012; Libby et al. 2002; Naghavi et al. 2003).

Address correspondence to: Jacques Ohayon, Laboratory TIMCIMAG/DyCTiM, UGA, CNRS UMR 5525, Grenoble, France. E-mail: jacques.ohayon@univ-grenoble-alpes.fr
To detect vulnerable plaques (VPs) in a timely manner and prevent adverse coronary events, several endovascular imaging techniques are available to clinicians or in development including intravascular ultrasound (IVUS) (Cheng et al. 2014; Rioufol et al. 2002), optical coherence tomography (Sinclair et al. 2015), magnetic resonance imaging (Cavalcante and Larose 2016; Larose et al. 2005) and near-infrared spectroscopy (Caplan et al. 2006; Madder et al. 2016), as well as emergent hybrid techniques that combine two or more imaging modalities (Abran et al. 2014; Bourantas et al. 
2017). Despite these technological advances, identifying which VPs will rupture and induce an acute event remains a challenging task.

Previous biomechanical studies have identified peak cap stress amplitude as a strong indicator of plaque vulnerability to rupture (Finet et al. 2004; Gijsen and Migliavacca 2014; Kok et al. 2016; Ohayon et al. 2008; Tang et al. 2009). Others have established that plaque rupture risk is also attributed to additional factors such as the presence of microcalcifications in the thin cap (Cardoso and Weinbaum 2014; Kelly-Arnold et al. 2013; Thondapu et al. 2017), plaque morphology (Akyildiz et al. 2016; Ohayon et al. 2008) and hemodynamics (Ahmadi et al. 2016; Gijsen et al. 2008; Morbiducci et al. 2016), as well as tissue mechanical properties of the atherosclerotic lesion (Guo et al. 2017; Finet et al. 2004; Ohayon et al. 2014).

Although plaque morphology and cap thickness can be directly extracted from endovascular images, the stress distribution within the plaque is impossible to obtain using current medical imaging technologies. However, the local deformation (strain) of the arterial wall and plaque caused by the cyclic intraluminal pressure can be calculated from a series of ultrasound images (Doyley 2012; Golemati et al. 2016; Maurice et al. 2004b). Based on the postulate that local variations in elastic properties of tissues are generally correlated with pathologic regions, strain elastography - a strain fieldbased technique - was developed. This approach was first introduced by Ophir's group (Cespedes et al. 1993; Ophir et al. 1991) to map the mechanical strain response to an applied force. Nevertheless, complex non-linear geometric effects do not allow a direct correlation between the measured spatial strain field and the mechanical property of the tissue. By using the IVUS strain field inside atherosclerotic plaques (De Korte et al. 2002; Doyley 2012; Maurice et al. 2004a, 2007), several elasticity reconstruction approaches have been developed to characterize the entire lesion (Baldewsing et al. 2007; Deléaval et al. 2013; Doyley 2012; Le Floc'h et al. 2009, 2010, 2012; Nayak et al. 2017; Poree et al. 2017; Richards and Doyley 2011; Richards et al. 2015; Tacheau et al. 2016) and to delineate a subendoluminal layer of the arterial wall called the palpography domain (Céspedes et al. 2000; Deléaval et al. 2013; Doyley et al. 2001; Schaar et al. 2005; Widynski et al. 2014). Both techniques aim to characterize the mechanical properties of atherosclerotic lesions and ultimately differentiate vulnerable from stable plaques.

In the latter elasticity-palpography technique originally developed by Céspedes et al. (2000) and Doyley et al. (2001), and revisited by our group to account for the anatomic shape of the VP (Deléaval et al. 2013), the apparent local stiffness of the subendoluminal arterial wall layer was computed assuming that all plaque constituents are elastically isotropic. Even though these studies highlighted promising results, they failed to address the anisotropic mechanical behavior of the arterial wall and atherosclerotic lesion (Holzapfel et al. 2005).

Therefore, the purpose of this study was to extend the theoretical framework of the palpography technique implemented by Deléaval et al. (2013) to account for the anisotropic mechanical behavior of the arterial wall. Based on the continuum mechanics theory prescribing the radial strain field, a new anisotropic elasticity-palpography technique (AE-PT) was successfully applied to five modeled plaque geometries, ten coronary lesions and one healthy vessel of patients imaged in vivo with IVUS. An elastic anisotropy index (AI) was extracted.

\section{METHODS}

Using images of patients who underwent coronary IVUS, cross-sectional geometries of ten atherosclerotic plaques and one healthy vessel were manually extracted based on the echogenicity aspect. Additionally, five idealized plaque morphologies were designed and simulated to validate the proposed AE-PT and to investigate the effects of cap thickness and palpography domain size on computed palpograms. Then, a 3-D finiteelement (FE) analysis was conducted for each plaque geometry to compute the exact displacement and strain field distributions. To validate the robustness of palpograms, we synthesized radiofrequency (RF) echo frames by combining the computed FE displacement field with an ultrasound simulation model based on the Field II software (Jensen and Svendsen 1992). For all simulated IVUS RF sequences, the radial strain elastograms were estimated with the Lagrangian speckle model estimator (Maurice et al. 2004a). These radial strain elastograms were used to obtain the inverse solution of palpograms for the IVUS mechanical characterization of anisotropic vascular tissues.

\section{IVUS study and plaque geometries}

Patient population. Vulnerable plaque geometries were extracted from IVUS images acquired on patients referred for percutaneous coronary intervention at the Louis Pradel Cardiology Hospital of Lyon after a first acute coronary syndrome with troponin I elevation. Patients' consent was obtained, and the study was approved by the ethical institutional review board of the Cardiology Hospital.

Intravascular ultrasound imaging. A set of one healthy and ten non-ruptured VP morphologies were collected from IVUS scans of the coronary arteries 
according to the protocol described by Rioufol et al. (2002). Cross-sectional IVUS images of the atherosclerotic lesions were recorded at sites exhibiting the thinner fibroatheroma cap or at sites with the largest degree of stenosis. IVUS scans were performed with the iLab platform (Boston Scientific, Watertown, MA, USA) equipped with 40-MHz catheters (Atlantis SR Pro 3.6 F, Boston Scientific) and a radial spatial resolution in B-mode of approximately $90 \mu \mathrm{m}$ (Chopard et al. 2010).

IVUS image analysis and plaque morphologic measurements. IVUS echogenicity aspects were used to characterize VP components according to the following observations: (i) highly hypo-echogenic components (or anechogenic zones), suggestive of lipid or cellular deposition; or (ii) homogeneous reflective components, suggestive of fibrosis (Di Mario et al. 1998). A manual segmentation procedure using ImageJ software (National Institutes of Health [NIH], Bethesda, MD, USA) was performed by a cardiologist to extract the internal (i.e., lumen) and external contours of the coronary cross section, as well as the contours of each plaque component (i.e., necrotic core and dense fibrosis).

The morphology of each IVUS lesion image was quantified for plaque area $\left(\mathrm{Pla}_{\text {area }}, \mathrm{mm}^{2}\right)$, lumen area $\left(\mathrm{Lu}_{\text {area }}, \mathrm{mm}^{2}\right)$, soft necrotic core area, dense fibrosis area and degree of stenosis $\left(\right.$ Stenos $\left._{\mathrm{deg}}, \%\right)$ as $100 \times \mathrm{Pla}_{\text {area }}$ $/\left(\mathrm{Pla}_{\text {area }}+\mathrm{Lu}_{\text {area }}\right)$ and cap thickness $\left(\mathrm{Cap}_{\text {thick }}, \mathrm{mm}\right)$, which was defined as the shortest distance between the lumen and the necrotic core.

Idealized geometries. One concentric and one eccentric idealized circular plaque geometries with homogeneous anisotropic and quasi-incompressible atherosclerotic lesions were simulated to validate the theoretical background of the AE-PT (Fig. 1). Moreover, to investigate the effects of cap thickness $\left(\mathrm{Cap}_{\text {thick }}\right)$ on the resulting anisotropic elasticity palpogram, plaque geometry acquired on a single patient (plaque \#2 with a Capthick of $93 \mu \mathrm{m}$ ) (Fig. 2) was modified by translating the soft necrotic inclusion radially (i.e., along the axis going from the center of mass of the vessel lumen to the center of mass of the necrotic core). Thus, three idealized pla-

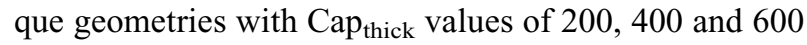
$\mu \mathrm{m}$ were modeled (plaques \#2A-2C) (Fig. 2).

\section{Forward problem: Spatial displacement and strain field distributions}

3-D finite-element simulations. The 2-D digitized contours obtained were transferred into Comsol software (Structural Mechanics Module, Version 4.3b, Comsol, France). To compute the deformed shape, a 3-D static FE simulation was conducted on each thin-sliced volumetric plaque (slice thickness $=0.1 \mathrm{~mm}$ ) obtained by extrusion of the cross-sectional plaque profile in the longitudinal direction of the artery. Each geometry was meshed with approximately 5000 six-node prism elements. The barycenter (i.e., the center of mass) of the luminal area was used as the origin of the cylindrical coordinate system $(R, \theta, Z)$.

Instantaneous pressures were not recorded during the clinical IVUS exploration of the coronary arteries. Therefore, a blood pressure differential amplitude $\Delta P$ between 0.3 and $1 \mathrm{kPa}$ (i.e., $2.2-7.5 \mathrm{mmHg}$ ) was assumed, corresponding to a realistic pressure gradient occurring between two successive images $\left(\mathrm{Im}^{i}\right.$ and $\mathrm{Im}^{i+1}$ ) of the IVUS sequence (Le Floc'h et al. 2009, 2012). In our computational approach, the deformation of the atherosclerotic plaque between $\operatorname{Im}^{i}$ and $\operatorname{Im}^{i+1}$ was obtained by considering the geometry of the lesion at $\mathrm{Im}^{i}$ as the reference configuration. Therefore, FE simulations were performed in linear elasticity with a small loading blood pressure differential $\Delta P$. A free boundary condition was assumed at the external wall of the artery, and sliding conditions were imposed on the two cross sections of the vessel segment $(R-\theta$ planes, $Z=0$ and $0.1 \mathrm{~mm}$ ). Such boundary conditions constrain the deformation to take place in the planes where $Z$ is equal to a constant. Additionally, displacement limitations were placed upon nodes located on the four cardinal directions of the external wall of the artery to avoid rigid rotations. These latter boundary conditions allow free-radial expansion of the vessel during pressure loading, resulting in more realistic vessel inflation kinematics.

The fibrotic plaque medium and the healthy coronary arterial wall were considered as orthotropic and quasi-incompressible media (Appendix I), with initial mechanical properties coming from measurements (Chagnon et al. 2017; Holzapfel et al. 2005) of the pathologic coronary thick intima layer and the adventitia layer, respectively. The mechanical properties of the dense fibrosis and soft necrotic cores were considered as isotropic and quasi-incompressible (Lee et al. 1991; Loree et al. 1994). Young's moduli, Poisson ratios and shear moduli for all media are summarized in Table 1.

Simulation of ultrasound images. The open source software Field II (Jensen and Svendsen 1992) was modified to simulate the IVUS acoustic field (Fromageau et al. 2003; Nayak et al. 2017; Poree et al. 2017). Briefly, biological tissues were characterized by their acoustic scattering amplitude. Acoustic models were built by randomly distributing scatterers over each non-deformed medium. The relative acoustic scatterer amplitudes of blood, necrotic core, fibrotic plaque and dense fibrosis were set to $10 \%, 15 \%, 35 \%$ and $60 \%$, respectively 

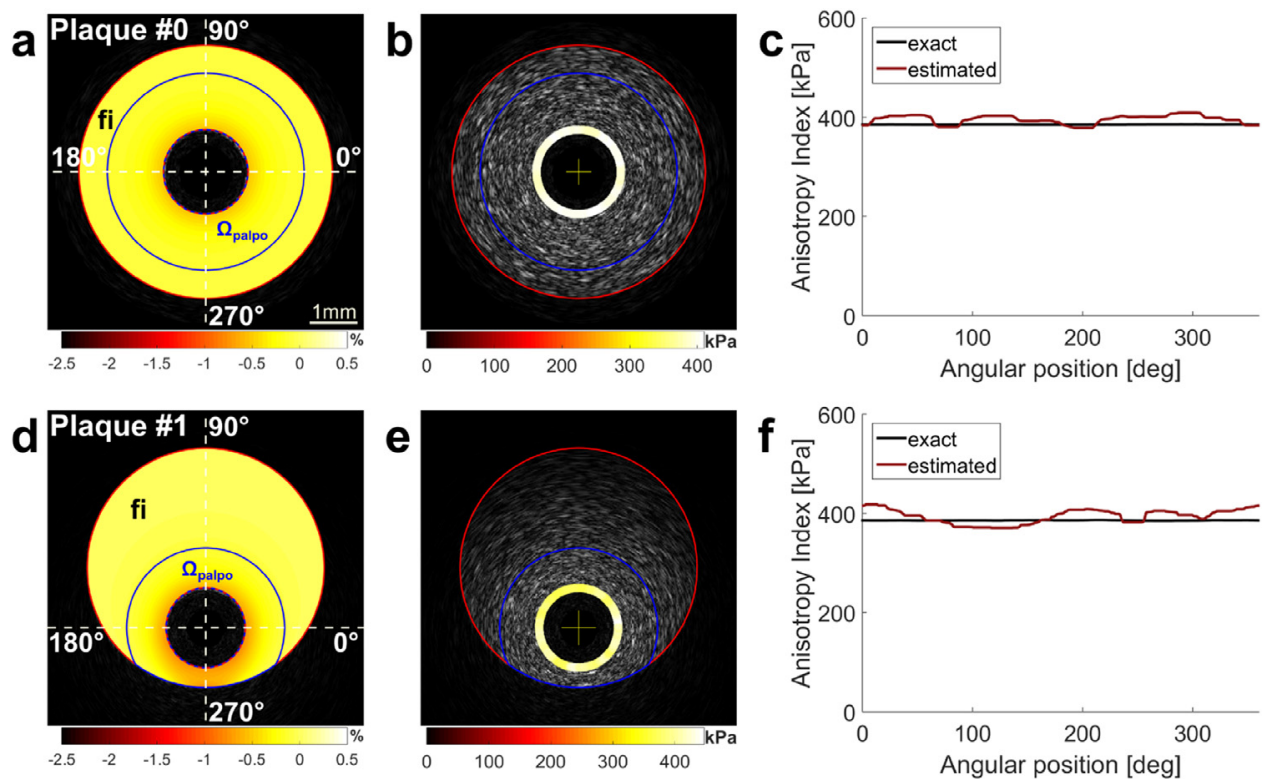

Fig. 1. Performance of the anisotropic elasticity-palpography technique on idealized homogeneous concentric and eccentric plaque models (plaques \#0 and 1, respectively). (a, d) Plaque geometries (red contours), palpography domains $\Omega_{\text {palpo }}$ (blue contours) and estimated radial strain elastograms. (b, e) Intravascular ultrasound images with anisotropy index-palpograms $A I(\theta)$. (c, f) Comparisons between exact and estimated $\mathrm{AI}(\theta)$ palpograms. fi = fibrotic plaque region.
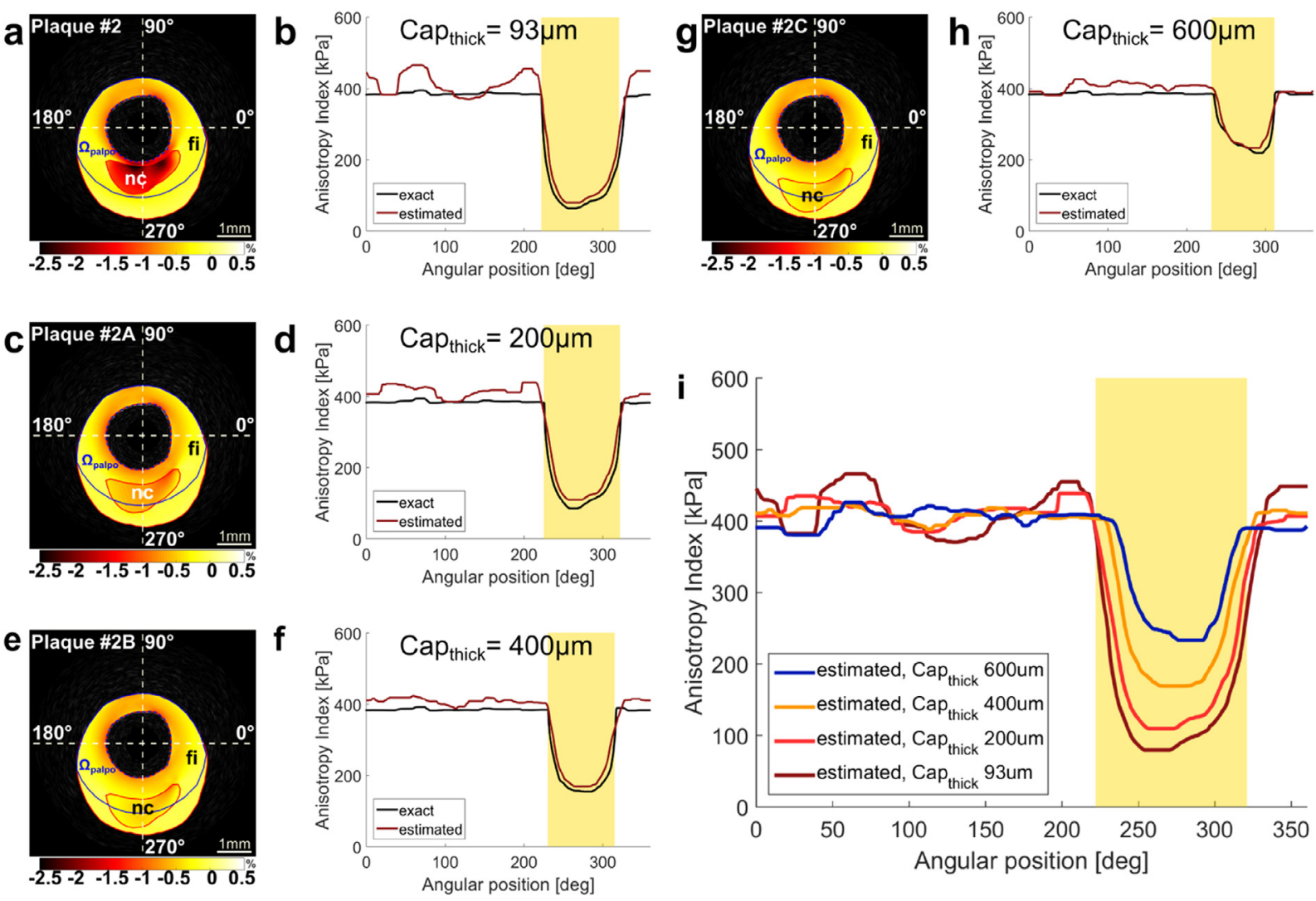

Fig. 2. Effect of cap thickness $\left(\mathrm{Cap}_{\mathrm{thick}}\right)$ on the resulting anisotropic elasticity palpogram $A I(\theta)$. Simulations were performed with plaque \#2. (a, c, e, g) Plaque geometries (red contours), palpography domains (blue contours) and estimated radial strain elastograms. (b, d, f, h) Comparisons between exact and estimated $\operatorname{AI}(\theta)$ palpograms. (i) Comparison between all estimated AI-palpograms. Areas shaded in yellow indicate the location of the necrotic core. $\mathrm{fi}=$ fibrotic plaque region; $\mathrm{nc}=$ necrotic core. 
Table 1. Orthotropic and isotropic mechanical properties and anisotropy index values assigned for the healthy wall, fibrous plaque, dense fibrosis and soft necrotic core inclusions

\begin{tabular}{|c|c|c|c|c|c|}
\hline & \multicolumn{3}{|c|}{ Young's modulus (kPa) } & \multirow[b]{2}{*}{ Anisotropy index $(\mathrm{kPa})$} & \multirow[b]{2}{*}{ Reference (medium) } \\
\hline & $E_{\mathrm{R}}$ & $E_{\theta}$ & $E_{\mathrm{Z}}$ & & \\
\hline Healthy wall & 120 & 80 & 170 & 121.8 & Holzapfel et al. (2005) (adventitia) \\
\hline \multicolumn{6}{|l|}{ Pathologic wall } \\
\hline Fibrous plaque & 360 & 230 & 330 & 384.3 & Holzapfel et al. (2005) (thick intima) \\
\hline Dense fibrosis* & & 1500 & & 2000 & Lee et al. (1991) \\
\hline Necrotic core* & & 5 & & 6.7 & Loree et al. (1994) \\
\hline
\end{tabular}

* Isotropic $\left(E_{\mathrm{R}}=E_{\theta}=E_{\mathrm{Z}}\right)$.

(Cardoso et al. 2014;Le Floc'h et al. 2010; Maurice et al. 2004a). First, an IVUS image of the non-deformed state (i.e., $\mathrm{Im}^{i}$ ) was created. Then the displacement field resulting from the FE simulation was used to track the location of scatterers and to create the postdeformation IVUS image (i.e., $\mathrm{Im}^{i+1}$ ). A single rotating piezo-electric element $(600-\mu \mathrm{m}$ diameter, $40-$ $\mathrm{MHz}$ central emission frequency) was modeled. An incremental circumferential rotation step of $0.7^{\circ}$ was set to get 512 lines of RF signal for IVUS image reconstruction. A sampling frequency of $400 \mathrm{MHz}$ was mimicked to represent the RF signal (SVMI HD IVUS system, ACIST Medical Systems, Eden Prairie, MN, USA). The arterial wall was also adjusted to set the centroid of the lumen coincident with the probe location.

Intravascular strain elastography. Sequences of simulated RF images were processed using the Lagrangian speckle model estimator. Radial strain fields were computed using a two-step strain imaging algorithm (Majdouline et al. 2014; Maurice and Bertrand 1999; Maurice et al. 2004a, 2007). First, a block matching method provides local registration on overlapping subwindows (measurement windows [MWs]). It allows compensating for rigid translation movements using a 2-D cross correlation coefficient. Once MW locations have been registered, the 2-D-deformation matrix is estimated. Estimation is based on the resolution of a firstorder optical flow equation for each MW (Majdouline et al. 2014). Sizes of MWs in radial and circumferential directions were set to 101 pixels (about $194.5 \mu \mathrm{m}$ ) and 21 pixels (about $14.8^{\circ}$ ). Shift between MWs was set to preserve an overlap of $90 \%$ in the radial and circumferential directions (Le Floc'h et al. 2010; Maurice et al. 2004a). Moreover, a sensitivity study was conducted to investigate the influence of MW size on the accuracy of the AI-palpograms. In agreement with the IVUS imaging studies of Céspedes et al. (2000), Doyley et al. (2001), Deléaval et al. (2013), Widynsky et al. (2014) and Tacheau et al. (2016), a palpography domain thickness close to $1 \mathrm{~mm}$ was used for our simulations, unless otherwise stated.

Inverse problem: The anisotropic elasticity-palpography technique

To account for the orthotropic mechanical properties of the vascular tissue, we defined an elastic anisotropy index (AI) as the ratio of the averaged difference between the radial and circumferential stresses $\left(\sigma_{R R}\right.$ and $\left.\sigma_{\theta \theta}\right)$ over the averaged radial strain $\left(\varepsilon_{R R}\right)$ along the radial axis:

$\mathrm{AI}(\theta)=\frac{\left|\int_{R_{i}(\theta)}^{R_{0}(\theta)}\left\{\sigma_{\mathrm{RR}}(R, \theta)-\sigma_{\theta \theta}(R, \theta)\right\} d R\right|}{\varepsilon(\theta)}$

with

$\varepsilon(\theta)=\left|\int_{R_{i}(\theta)}^{R_{o}(\theta)} \varepsilon_{\mathrm{RR}}(R, \theta) d R\right|$

where $R_{\mathrm{i}}(\theta)$ and $R_{\mathrm{o}}(\theta)$ are the inner and outer radii of the considered palpography domain, respectively. Appendix II provides the details of the computation of this index.

Note that the amplitude of $\operatorname{AI}(\theta)$ remains constant and equal to

$\mathrm{AI}(\theta)=E_{R}^{0}\left[1-\frac{1}{4}\left(1-\frac{E_{R}^{0}}{E_{\theta}^{0}}+\frac{E_{R}^{0}}{E_{Z}^{0}}\right)\left(1+\frac{E_{Z}^{0}}{E_{R}^{0}}-\frac{E_{Z}^{0}}{E_{\theta}^{0}}\right)\right]^{-1}$

when considering a homogeneous pathologic lesion made of the same incompressible orthotropic medium (i.e., when $E_{R}(R, \theta)=E_{R}^{0}, \quad E_{\theta}(R, \theta)=E_{\theta}^{0} \quad$ and $\left.E_{Z}(R, \theta)=E_{Z}^{0}\right)$, whatever the plaque geometry and the palpography domain $\Omega_{\text {palpo considered (with }}$ $\left.R_{\mathrm{i}}(\theta) \leq R \leq R_{\mathrm{o}}(\theta)\right)$.

For a homogeneous incompressible transversely isotropic lesion (i.e., when $E_{R}(R, \theta)=E_{R}^{0}$ and $\left.E_{Z}(R, \theta)=E_{\theta}(R, \theta)=E_{\theta}^{0}\right)$, the $\mathrm{AI}$ amplitude is reduced to the constant

$A I=\frac{4 E_{R}^{0^{2}}}{4 E_{R}^{0}-E_{\theta}^{0}}$ 
and to $\mathrm{AI}=4 E / 3$ for a homogeneous incompressible isotropic plaque (i.e., when $E_{R}(R, \theta)=E_{\theta}(R, \theta)=E_{Z}(R, \theta)=E$ ).

Table 1 gives the amplitudes of the AI for the considered mechanical properties of the adventitia (healthy arterial wall), thick intima (fibrotic plaque), dense fibrosis and soft necrotic media.

Method used to verify the accuracy of the anisotropic elasticity-palpography technique. Two anisotropic index palpograms were computed: the first, $A I(\theta)$, with the estimated radial strain elastogram, and the second, $\mathrm{AI}^{*}(\theta)$, considering the exact radial strain map. To investigate the accuracy of each palpogram (i.e., $\operatorname{AI}(\theta)$ and $\mathrm{AI}^{*}(\theta)$ ), we compared them with the exact circumferential distribution of the averaged anisotropic material constant $C(R, \theta)$ along the radial axis:

$\mathrm{AI}^{\text {exact }}(\theta)=\frac{1}{R_{0}(\theta)-R_{i}(\theta)} \int_{R_{i}(\theta)}^{R_{o}(\theta)} C(R, \theta) d R$

and we computed two mean relative anisotropy index errors $\left(\mathrm{MR}_{\mathrm{error}}^{\mathrm{AI}}\right.$ and $\left.\mathrm{MR}_{\text {error }}^{\mathrm{AI}}\right)$ :

$\mathrm{MR}_{\text {error }}^{\mathrm{K}(\theta)}(\%)=\frac{100}{2 \pi} \int_{\theta=0}^{2 \pi}\left|\frac{\mathrm{K}(\theta)-A I^{\text {exact }}(\theta)}{A I^{\text {exact }}(\theta)}\right| d \theta$,

with $\mathrm{K}(\theta)=\operatorname{AI}(\theta)$ or $\mathrm{AI}^{*}(\theta)$

$\mathrm{MR}_{\text {error }}^{\mathrm{AI}^{*}}$ indicates the best accuracy that could be reached when using the new anisotropic palpography technique, and $\mathrm{MR}_{\text {error }}^{\mathrm{AI}}$ quantifies the cumulative error induced by both the proposed palpography technique and the estimated radial strain elastogram. Therefore, to quantify the error induced only by the radial strain elastogram estimation on the AI-palpogram, we defined the following mean relative error $\left(\mathrm{MR}_{\text {error }}^{\mathrm{AI} / \mathrm{AI} *}\right)$ :

$\mathrm{MR}_{\text {error }}^{\mathrm{AI} / \mathrm{AI}^{*}}(\%)=\frac{100}{2 \pi} \int_{\theta=0}^{2 \pi}\left|\frac{\mathrm{AI}(\theta)-\mathrm{AI}^{*}(\theta)}{\mathrm{AI}^{*}(\theta)}\right| d \theta$

\section{RESULTS}

\section{IVUS study}

Seven non-ruptured VPs with soft necrotic cores, one homogeneous plaque, two atherosclerotic lesions with dense fibrosis inclusions and one non-pathologic cross section were identified after extensive IVUS scanning. The geometric characteristics of these 11 cross sections scanned in vivo are summarized in Table 2. All computed AI-palpograms presented in the figures were obtained from radial strain elastograms estimated from sequences of simulated RF images.
Performance of the anisotropic elasticity-palpography technique

Validation cases and AI-palpogram accuracies. Simulations were performed on the idealized concentric and eccentric plaque geometries with homogeneous orthotropic and quasi-incompressible fibrotic atherosclerotic plaques (Fig. 1). AI-palpograms for the concentric and eccentric plaques remain almost constant with mean values ( \pm standard deviation [SD]) of $396 \pm 9$ and 394 $\pm 14 \mathrm{kPa}$, both close to the expected theoretical value $(\mathrm{AI}=384.3 \mathrm{kPa}$, Table 1) given by eqn (3) - even in the high-strained free-plaque arc length of the eccentric plaque geometry, which is the thinnest region of the palpography domain (i.e., between the angular positions $180^{\circ}$ and $360^{\circ}$, Figs. 1e, f). The small amplitudes of the mean relative anisotropy index errors $\left(\mathrm{MR}_{\mathrm{error}}^{\mathrm{AI}}=3.08 \%\right.$ and $3.70 \%$, Table 3), together with the small amplitudes of the standard deviations $(\mathrm{SD}=1.62 \%$ and $2.08 \%$, Table 3), highlight the robustness of the AE-PT algorithm with respect to the IVUS RF sequences when estimating AI-palpograms for concentric and eccentric plaque morphologies, respectively. More generally, the results revealed that all 18 AI-palpograms were estimated with reasonable accuracy (with a mean relative error $\mathrm{MR}_{\text {error }}^{\mathrm{AI}}=26.79 \pm 48.84 \%$, Table 3) when compared with the exact ones and with a good robustness with respect to the estimated strain-elastogram, as reflected by the mean relative error $\mathrm{MR}_{\text {error }}^{\mathrm{AI} / \mathrm{AI}^{*}}=10.24 \pm$ $14.43 \%$ (Table 3 ).

Detection and characterization of vulnerable plaques with soft inclusions. AI-palpograms were computed for VPs with one (plaques \#2, 2A-2C and 12-15, Figs. 2-4) and two distinct (plaques \#16 and 17, Fig. 5) necrotic cores. These AI-palpograms were estimated with a mean relative error of $34.36 \pm 57.03 \%$ (Table 3 ). Locations of the necrotic core sites were accurately detected using the AE-PT. The AI-palpogram amplitudes were found close to the AI value of the fibrotic plaque (i.e., close to $384.3 \mathrm{kPa}$, Table 1) except at soft inclusion locations, for which the AI amplitudes were found to be significantly lower, as expected (Figs. 2-4).

Detection and characterization of stable plaques with dense fibrosis inclusions. For one stable plaque (plaque \#19, Fig. 6) with one isolated dense fibrosis inclusion, the proposed palpography technique detected and distinguished the fibrotic plaque from dense fibrosis. Compared with the exact value, the estimated AI amplitude at the dense fibrosis inclusion location was underestimated by almost a factor of 2 . 
Table 2. Characteristics of the IVUS-detected and modelled atherosclerotic plaques and healthy artery used to test the performance of the proposed anisotropic elasticity-palpography technique.

\begin{tabular}{|c|c|c|c|c|c|c|c|}
\hline \multirow[b]{2}{*}{ Plaque No. } & \multirow[b]{2}{*}{ Origin of geometry } & \multirow[b]{2}{*}{ Cap thickness* $(\mu \mathrm{m})$} & \multicolumn{4}{|c|}{ Area $\left(\mathrm{mm}^{2}\right)$} & \multirow[b]{2}{*}{ Stenosis (\%) } \\
\hline & & & Necrotic core & Dense fibrosis & Plaque & Lumen & \\
\hline 0 & Model & - & - & - & 14.14 & 1.77 & 89 \\
\hline 1 & Model & - & - & - & 25.13 & 3.14 & 89 \\
\hline 2 & IVUS & 93 & 1.36 & - & 8.74 & 2.79 & 76 \\
\hline $2 \mathrm{~A}$ & Model & 200 & 1.36 & - & 8.74 & 2.79 & 76 \\
\hline $2 \mathrm{~B}$ & Model & 400 & 1.36 & - & 8.74 & 2.79 & 76 \\
\hline $2 \mathrm{C}$ & Model & 600 & 1.36 & - & 8.74 & 2.79 & 76 \\
\hline Healthy 1 & IVUS & - & - & - & 8.45 & 11.87 & 42 \\
\hline 11 & IVUS & - & - & - & 9.88 & 7.59 & 57 \\
\hline 12 & IVUS & $<90(55)$ & 3.48 & - & 14.24 & 6.06 & 70 \\
\hline 13 & IVUS & $<90(63)$ & 4.41 & - & 15.48 & 4.28 & 78 \\
\hline 14 & IVUS & $<90(49)$ & 1.97 & - & 19.38 & 6.80 & 74 \\
\hline 15 & IVUS & $<90(48)$ & 1.89 & - & 17.29 & 8.44 & 67 \\
\hline 16 & IVUS & 100 & $1.41 / 0.46$ & - & 19.50 & 7.67 & 72 \\
\hline 17 & IVUS & $<90(65)$ & $2.20 / 0.53$ & - & 29.53 & 4.34 & 87 \\
\hline 18 & IVUS & $<90(60)$ & - & 1.36 & 6.34 & 5.99 & 51 \\
\hline 19 & IVUS & $<90(88)$ & - & 0.90 & 5.31 & 5.35 & 50 \\
\hline
\end{tabular}

IVUS = intravascular ultrasound.

* Cap thickness was randomly assigned (value in parentheses) when found to be under the limit of the B-mode spatial resolution obtained with the 40-MHz IVUS catheter (i.e., $<90 \mu \mathrm{m})$.

Detection and characterization of homogeneous stable plaques and healthy vessel wall. AI-palpograms were also computed for one eccentric homogeneous stable plaque (plaque \#11, Fig. 7) and one healthy coronary wall (healthy \#1, Fig. 8). The AE-PT successfully characterized the orthotropic mechanical properties of the pathologic lesion (made of fibrotic plaque tissue) and of the non-pathologic coronary artery. The two AI-palpograms were found almost constant with mean values $( \pm \mathrm{SD})$ of $360 \pm 15$ and $134 \pm 9 \mathrm{kPa}$, close to the expected theoretical values: $\mathrm{AI}=384.3$ and $121.8 \mathrm{kPa}$ for the pathologic and healthy arteries, respectively (Table 1).

\section{Effects of Cap thick $_{\text {on }}$ estimated AI-palpogram.}

For a given palpography domain, the Cap thick significantly affects the AI-palpogram at the soft inclusion location (plaques $\# 2$ and $2 A-2 C$, Fig. 2). Simulations performed with the idealized VP models in which the Cap $_{\text {thick }}$ increases from 93 to $600 \mu \mathrm{m}$ revealed that the

Table 3. Accuracy of the proposed anisotropic elasticity-palpography technique and effect of the estimated radial strain elastogram (computed with a measurement window size of $101 \times 21$ pixels) on the estimated AI-palpograms*

\begin{tabular}{|c|c|c|c|c|c|c|}
\hline Plaque No. & $\mathrm{NC}$ & $\mathrm{DF}$ & $\mathrm{H}$ & $\mathrm{MR}_{\text {error }}^{\mathrm{AI}^{*}}(\%)$ & $\mathrm{MR}_{\text {error }}^{\mathrm{AI}}(\%)$ & $\mathrm{MR}_{\text {error }}^{\mathrm{AI} / \mathrm{AI}^{*}(\%)}$ \\
\hline 0 & - & - & $\checkmark$ & $0.22 \pm 0.14$ & $3.08 \pm 1.62$ & $2.9 \pm 1.49$ \\
\hline 1 & - & - & $\checkmark$ & $3.72 \pm 1.72$ & $3.7 \pm 2.08$ & $4.24 \pm 3.2$ \\
\hline 2 & $\checkmark$ & - & - & $4.86 \pm 4.53$ & $13.41 \pm 9.45$ & $8.76 \pm 6.06$ \\
\hline $2 \mathrm{~A}$ & $\checkmark$ & - & - & $5.97 \pm 5.26$ & $11.13 \pm 7.9$ & $5.53 \pm 4.28$ \\
\hline $2 \mathrm{~B}$ & $\checkmark$ & - & - & $3.74 \pm 2.29$ & $7.84 \pm 4.35$ & $4.22 \pm 3.06$ \\
\hline $2 \mathrm{C}$ & $\checkmark$ & - & - & $1.91 \pm 1.55$ & $5.05 \pm 3.85$ & $4.03 \pm 2.79$ \\
\hline Healthy 1 & - & - & $\checkmark$ & $0.65 \pm 0.5$ & $10.03 \pm 7.67$ & $10.49 \pm 7.66$ \\
\hline 11 & - & - & $\checkmark$ & $2.45 \pm 2.24$ & $6.66 \pm 3.55$ & $5.91 \pm 3.43$ \\
\hline 12 & $\checkmark$ & - & - & $21.71 \pm 27.64$ & $33.16 \pm 52.64$ & $16.4 \pm 19.1$ \\
\hline $13(0.75)$ & $\sqrt{ }$ & - & - & $66.6 \pm 52.63$ & $83.23 \pm 71.73$ & $16.1 \pm 21.47$ \\
\hline 13 & $\checkmark$ & - & - & $59.43 \pm 57.53$ & $74.14 \pm 67.96$ & $15.98 \pm 18.61$ \\
\hline $13(1.25)$ & $\checkmark$ & - & - & $36.96 \pm 41.17$ & $46.45 \pm 55.68$ & $15.84 \pm 17.44$ \\
\hline 14 & $\checkmark$ & - & - & $35.21 \pm 62.45$ & $44.87 \pm 78.06$ & $9.96 \pm 11.05$ \\
\hline 15 & $\checkmark$ & - & - & $35.54 \pm 73.87$ & $45.19 \pm 92.07$ & $8.49 \pm 7.47$ \\
\hline 16 & $\checkmark$ & - & - & $8.72 \pm 9.57$ & $14.46 \pm 17.38$ & $8.11 \pm 9.05$ \\
\hline 17 & $\sqrt{ }$ & - & - & $24.86 \pm 22$ & $33.3 \pm 33.19$ & $8.36 \pm 9.24$ \\
\hline 18 & - & $\checkmark$ & - & $11.32 \pm 12.96$ & $35.34 \pm 31.27$ & $29.5 \pm 31.75$ \\
\hline 19 & - & $\checkmark$ & - & $3.76 \pm 6.38$ & $11.25 \pm 8.91$ & $9.43 \pm 6.69$ \\
\hline Mean \pm SD & & & & $18.2 \pm 37.99$ & $26.79 \pm 48.84$ & $10.24 \pm 14.43$ \\
\hline
\end{tabular}

$\mathrm{AI}=$ anisotropy index $\mathrm{DF}=$ dense fibrosis; $\mathrm{H}=$ homogeneous; $\mathrm{NC}=$ necrotic core; $\mathrm{SD}=$ standard deviation.

* See eqns (6) and (7) for definitions of the mean relative errors $\mathrm{MR}_{\mathrm{error}}^{\mathrm{AI}}, \mathrm{MR}_{\mathrm{error}}^{\mathrm{AI}}$ and $\mathrm{MR}_{\mathrm{error}}^{\mathrm{AI} / \mathrm{Al}^{*}}$. Palpography thickness is $1 \mathrm{~mm}$ unless otherwise indicated in parentheses beside the plaque number. 

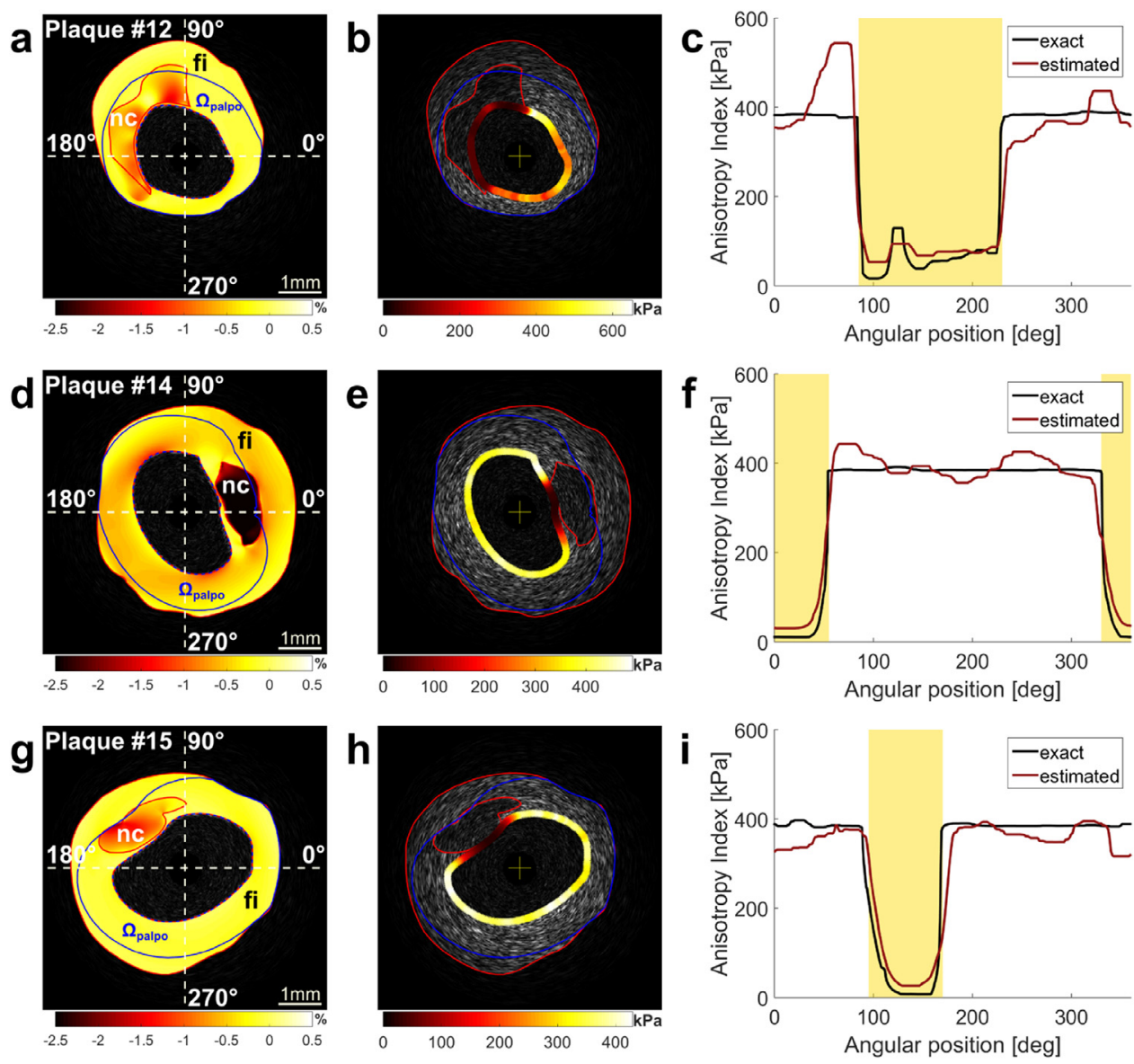

Fig. 3. Performance of the anisotropic elasticity palpography technique in detection of vulnerable plaques with one necrotic core (plaques \#12, 14 and 15). (a, d, g) Plaque geometries (red contours), palpography domains (blue contours) and estimated radial strain-elastograms. (b, e, h) IVUS images with anisotropy index-palpograms $\operatorname{AI}(\theta)$. (c, f, i) Comparisons between exact and estimated $\operatorname{AI}(\theta)$ palpograms. Areas shaded in yellow indicate the locations of the necrotic cores.

$\mathrm{fi}=$ fibrotic plaque region; $\mathrm{nc}=$ necrotic core.

mean AI amplitude at the location of the necrotic core increased from $139 \pm 74$ to $300 \pm 65 \mathrm{kPa}$ (Fig. 2).

\section{Effects of the palpography domain size on estimated} AI amplitude. We computed the AI-palpograms for the same VP considering three palpography domains with maximum thicknesses of $0.75,1$ and $1.25 \mathrm{~mm}$ (plaque \#13, Fig. 4). Increasing the palpography domain thickness from 0.75 to $1.25 \mathrm{~mm}$ improved the accuracy of the AI palpogram from $\mathrm{MR}_{\text {error }}^{\mathrm{AI}}=83.23 \pm 71.73 \%$ to $\mathrm{MR}_{\mathrm{error}}^{\mathrm{AI}}=46.45 \pm 55.68 \%$, respectively. The location of the necrotic core site was accurately detected using all palpography domains.

Sensitivity of AI-palpograms to the accuracy of the estimated strain elastograms. Because the MW size is one of the main parameters driving the accuracy of the computed strain elastograms, we restricted our sensitivity analysis to this parameter. These computations were performed on the stable plaque \#18 with one dense fibrosis inclusion and by considering three MW sizes: $75 \times 15$ pixels (i.e., 144.4 $\left.\mu \mathrm{m} \times 10.6^{\circ}\right), 101 \times 21$ pixels (i.e., $194.5 \mu \mathrm{m} \times 14.8^{\circ}$ ) and $121 \times 31$ pixels (i.e., $232.9 \mu \mathrm{m} \times 21.8^{\circ}$ ). An important palpogram variation was found at the freeplaque arc length. Only for this particular plaque, the AI-palpogram obtained with $(101 \times 21$ pixels $)$ MW size fail to characterize the atherosclerotic lesion, indicating that the accuracy of the AI-palpogram depends on the MW size used when estimating the radial strain elastogram (Fig. 9).

\section{DISCUSSION}

The new intraluminal ultrasonic palpation imaging technique successfully quantified the apparent wall stiffness of the anisotropic vascular wall based on the arterial radial strain and blood pressure data set. 

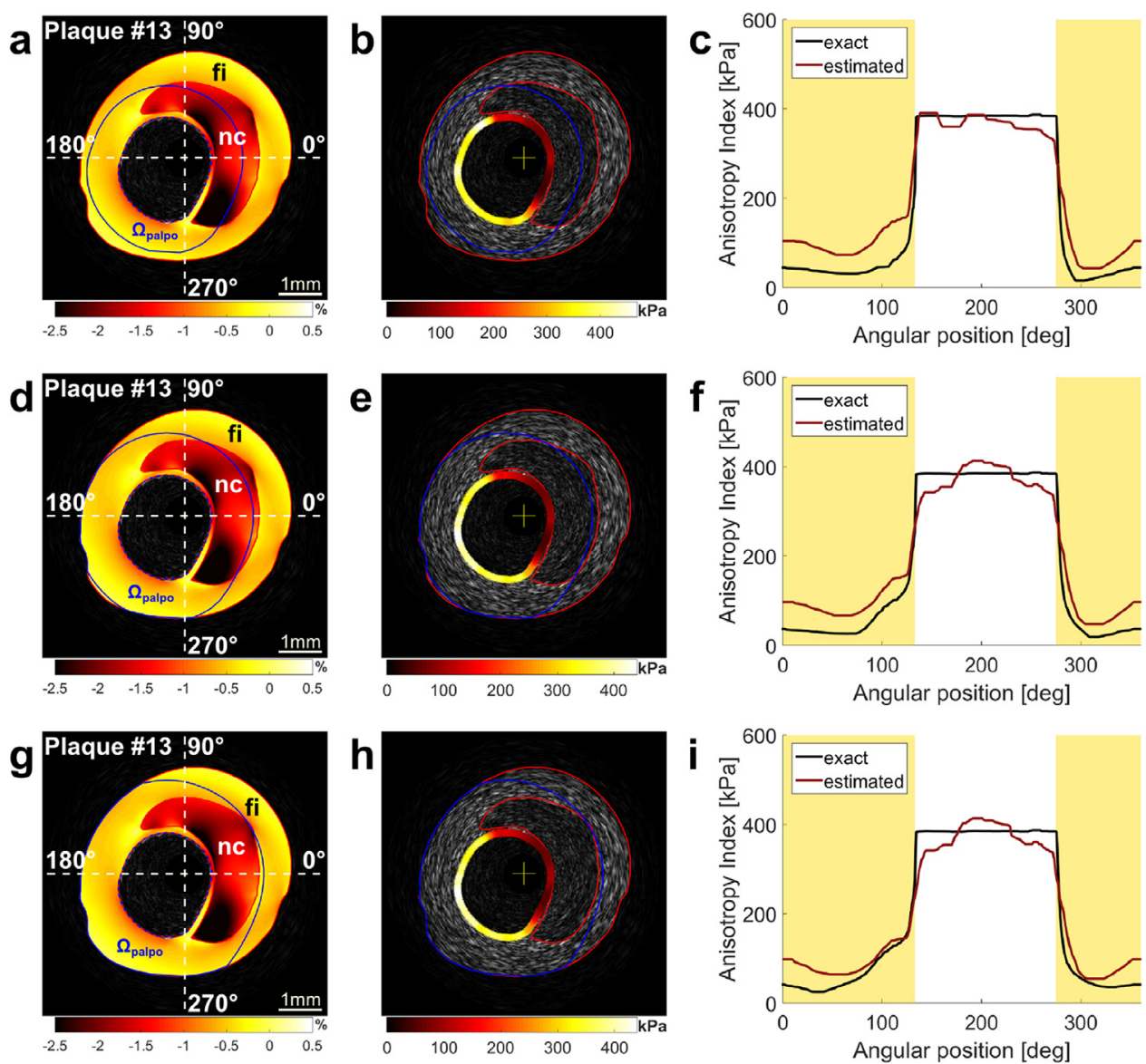

Fig. 4. Effect of palpography domain size on the resulting anisotropic elasticity palpogram. Simulations were performed with plaque \#13 considering three palpography domain thicknesses. (a, d, g) Plaque geometries (red contours); estimated radial strain-elastograms and palpography domains with thicknesses of $0.75,1$ and $1.25 \mathrm{~mm}$, respectively (blue contours). (b, e , h) Intravascular ultrasound images with anisotropy index-palpograms $\operatorname{AI}(\theta)$. (c, $\mathrm{f}, \mathrm{i})$ Comparisons between exact and estimated $\operatorname{AI}(\theta)$ palpograms. Areas shaded in yellow indicate the location of the necrotic core. $\mathrm{fi}=$ fibrotic plaque region; $\mathrm{nc}=$ necrotic core.

\section{Physical meaning of the elastic anisotropy index AI}

One of the advantages of AI, which may be viewed as an anisotropic apparent modulus, is to account for the three Young's moduli of the orthotropic atherosclerotic lesion. Even though the AE-PT does not allow identifying individually the three orthotropic material constants, this index, which combines the three orthotropic Young's moduli, is proportional to the radial Young's modulus and depends on the two stiffness ratios: $k_{1}=E_{\theta} /$ $E_{\mathrm{R}}$ and $k_{2}=E_{Z} / E_{R}$. Equation (3) indicates that the normalized elastic anisotropy index $\mathrm{AI} / E_{R}$ increases with $k_{2}$ and decreases with $k_{1}$ when $0.5 \leq k_{i} \leq 2(i=1,2)$. In other words, an increase in AI may be due to either an increase in $E_{R}$ and $E_{Z}$ or a decrease in $E_{\theta}$. Furthermore, the AI amplitude appears to be very sensitive to the presence of mechanical heterogeneities, dropping significantly when predicting soft inclusions in the composite atherosclerotic lesions (Figs. 2-5).

\section{$A E-P T$ highlights the non-linear mechanical response} of the vascular tissue

Because the proposed constitutive model refers to the configuration of the plaque at $\operatorname{Im}^{i}$, rather than the initial zero-stress configuration, the linear tangent elasticity procedure used in our approach (Bonet and Wood 1997) remains acceptable as long as the absolute amplitudes of the incremental strain components estimated between the two successive IVUS images $\operatorname{Im}^{i}$ and $\operatorname{Im}^{i+1}$ remain small ( $\leq 2 \%$ ) (Le Floc'h et al. 2012). Therefore, the computed AI must be viewed as an anisotropic linearized tangent modulus (Holzapfel 2000) measured for the physiologic pressure range considered. The other advantage of such an incremental linearized technique applied on a series of IVUS images is that it allows quantification of the non-linear mechanical response of the fibrotic plaque tissue during the physiologic increase in blood pressure. 

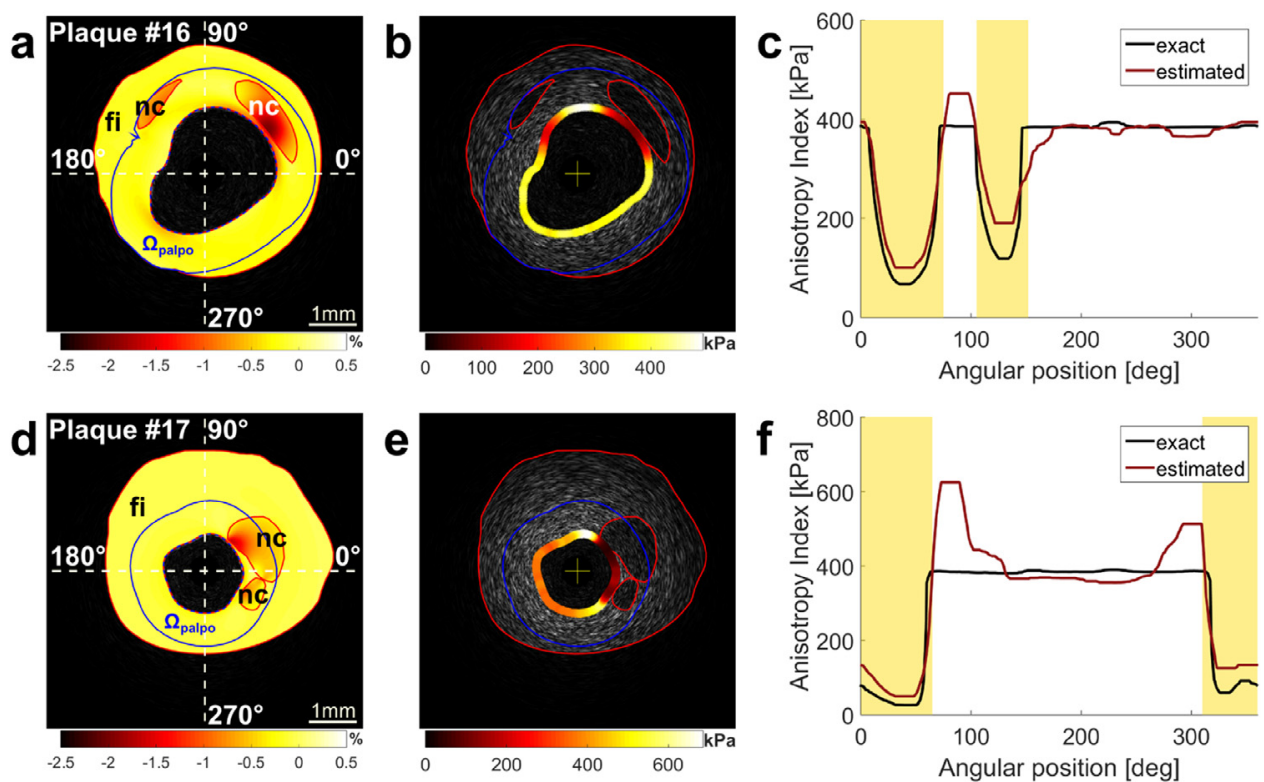

Fig. 5. Performance of the anisotropic elasticity-palpography technique in detection of vulnerable plaques with two necrotic cores (plaques \#16 and 17). (a, d) Plaque geometries (red contours), palpography domains (blue contours) and estimated radial strain elastograms. (b, e) intravascular ultrasound images with anisotropy index-palpogram $\operatorname{AI}(\theta)$. (c, f) Comparisons between exact and estimated $\operatorname{AI}(\theta)$ palpograms. Areas shaded in yellow indicate the locations of the two necrotic cores. $\mathrm{fi}=$ fibrotic plaque region; $\mathrm{nc}=$ necrotic core

\section{How should cardiologists choose the palpography domain?}

With the AE-PT, the interventional cardiologist may define the palpography domain by considering any arbitrary endoluminal thick layer size and shape. The results clearly indicated that an increase in the palpography domain thickness does not necessarily decrease the accuracy of the AI-palpogram (see Table 3 and Fig. 4, plaque \#13). This could be explained by the fact that the palpography domain must be thin enough to obtain a reasonable signal-tonoise (SNR) ratio (Céspedes et al. 2000; Doyley et al. 2001) and large enough for a good performance of the strain imaging algorithm (Maurice et al. 2004a).
What is the advantage of using the AI instead of the fractional anisotropy index for characterizing a VP?

The principal strain and fractional strain anisotropy indexes are two other strain-based metrics that were defined and applied in non-invasive clinical cardiovascular magnetic resonance imaging and ultrasound studies (Nayak et al. 2017; Soleimanifard et al. 2010). However, extracting the anisotropic mechanical properties of the tissue from these indexes is difficult. Furthermore, although the estimations of these indexes require accurate knowledge of all strain tensor components, estimation of the AI requires only the radial strain component, which is the only component that can be extracted from the coronary RF-IVUS signal with reasonable accuracy.
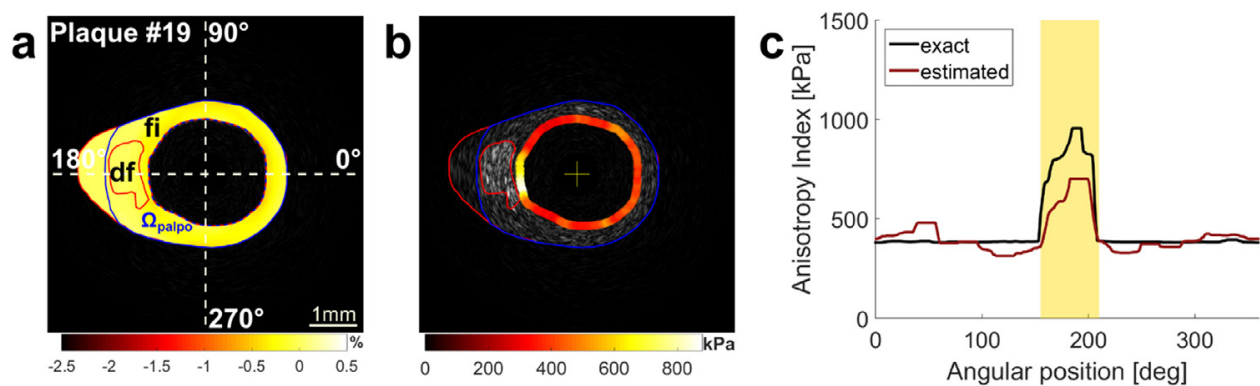

Fig. 6. Performance of the anisotropic elasticity-palpography technique in detection of a stable plaque with one dense fibrosis inclusion (plaque \#19). (a) Plaque geometry (red contour), palpography domain (blue contour) and estimated radial strain elastogram. (b) Intravascular ultrasound images with anisotropy index-palpogram $\mathrm{AI}(\theta)$. (c) Comparison between exact and estimated $\mathrm{AI}(\theta)$ palpograms. Area shaded in yellow indicates the location of the dense fibrosis inclusion. $\mathrm{df}=$ dense fibrosis. $\mathrm{fi}=$ fibrotic plaque region. 

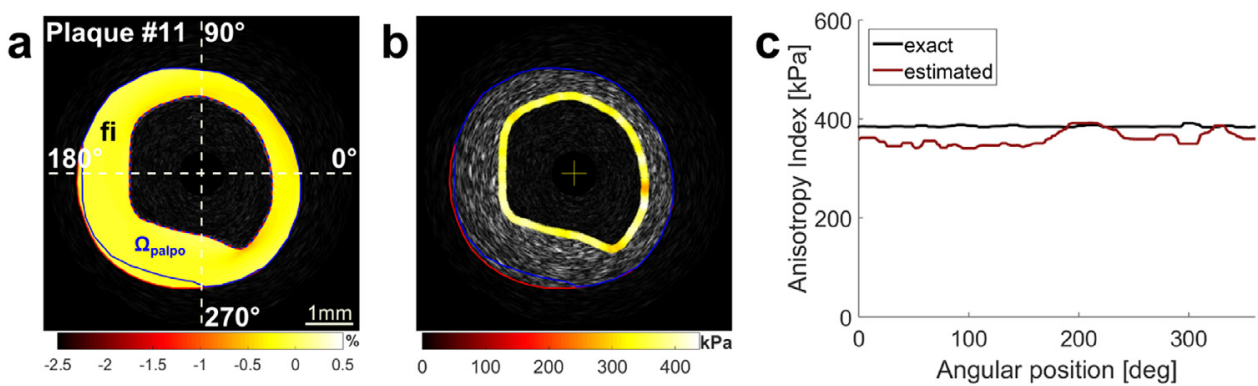

Fig. 7. Performance of the anisotropic elasticity-palpography technique in detection of a stable homogeneous fibrotic plaque (plaque \#11). (a) Plaque geometry (red contours), palpography domain (blue contours) and estimated radial strain elastogram. (b) Intravascular ultrasound image with the anisotropy index-palpogram $\operatorname{AI}(\theta)$. (c) Comparison between the exact and estimated $\operatorname{AI}(\theta)$ palpograms. $\mathrm{fi}=$ fibrotic plaque region.
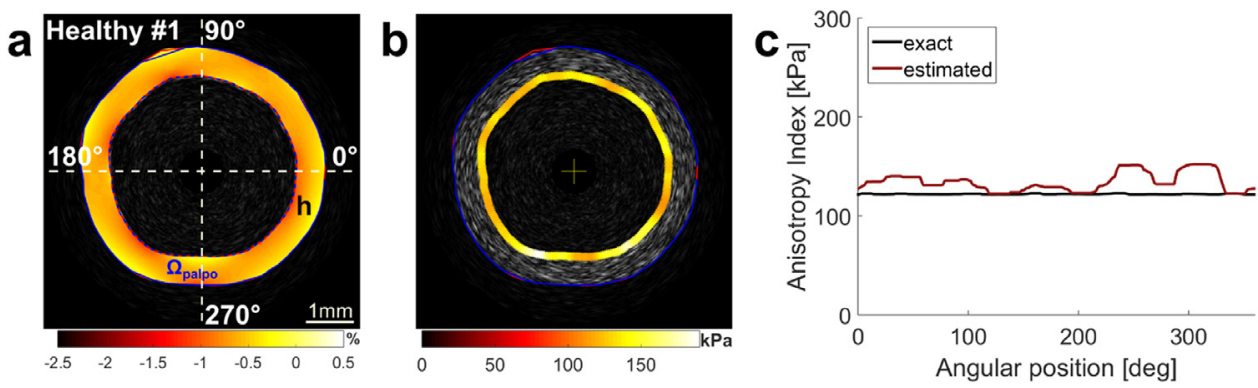

Fig. 8. Performance of the anisotropic elasticity-palpography technique in characterization of a healthy coronary cross section (healthy 1). (a) Artery geometry (red contours), palpography domain (blue contours) and estimated radial strain elastogram. (b) Intravascular ultrasound image with the anisotropy index-palpogram $\operatorname{AI}(\theta)$. (c) Comparison between the exact and the estimated $\mathrm{AI}(\theta)$. palpograms.

Is the AE-PT sufficient to detect VPs and diagnose plaque rupture?

The proposed AE-PT cannot diagnose the degree of plaque vulnerability to rupture because it does not allow measurements of other key geometric factors (Cilla et al. 2012; Ohayon et al. 2008). However, this technique remains reliable for detecting and highlighting complex VPs with one or several soft inclusions (see Figs. 2-5).
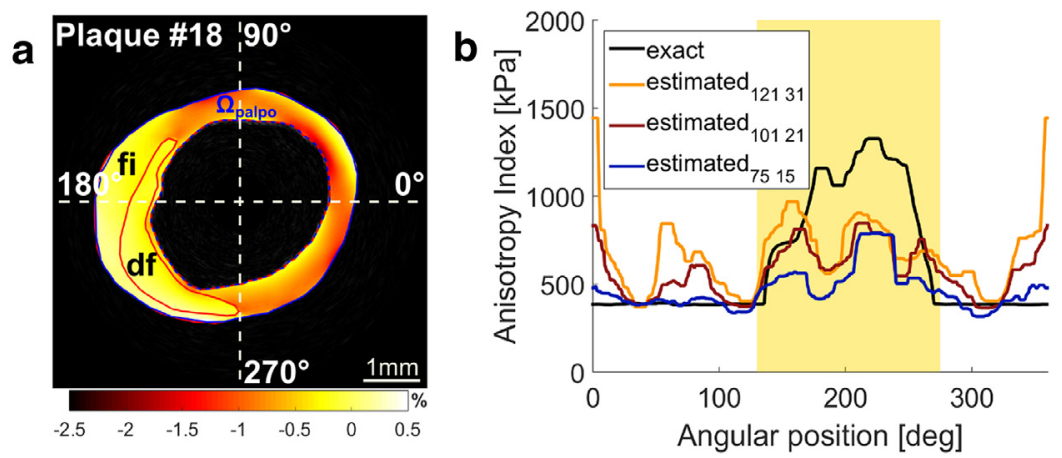

Fig. 9. Sensitivity analysis revealing the influence of measurement window (MW) size on the computed anisotropy index-palpogram $\operatorname{AI}(\theta)$. All these computations were performed on the dense fibrotic plaque \#18. Three MW sizes were considered for these simulations: $75 \times 15$ pixels, $101 \times 21$ pixels and $121 \times 31$ pixels. (a) Artery geometry (red contour), palpography domain (blue contour) and estimated radial strain map obtained with the $101 \times 21$-pixels MW size. (b) Comparison between exact and estimated $\operatorname{AI}(\theta)$ palpograms. The area shaded in yellow indicates the location of the dense fibrosis inclusion. $\mathrm{df}=$ dense fibrosis; $\mathrm{fi}=$ fibrotic plaque region. 


\section{Study limitations}

Several limitations deserve to be pointed out. First, the anisotropic palpation technique was tested and validated only on synthesized RF echo frames. Although further animal and clinical studies are needed to extend and strengthen the present findings, our preliminary results appear to be promising and indicate the potential and feasibility of this novel imaging technique. The second limitation of this study is that the palpography model neglected the residual strain, which has a significant effect on the stress amplitude in the thin fibrous cap (Ohayon et al. 2007). However, because the AI is an anisotropic linearized tangent modulus (Holzapfel 2000) measured during physiologic conditions, it implicitly accounts for all existing internal stresses/strains, including the residual ones. Finally, one clinical case presented in this study (plaque \#18, Fig. 9) highlighted the importance of considering optimal MW sizes to compute accurate AI-palpograms. A more exhaustive study clearly deserves to be investigated as future work to define an MW size that would optimize the performance of the strain-imaging algorithm of Majdouline et al. (2014).

\section{Relevance to other clinical applications}

Modifying the mechanical properties of the vulnerable atherosclerotic lesion could be the key issue for the stabilization of VPs. Finet et al. (2004) reported that a very slight increase in soft necrotic core stiffness can tilt a VP from instability to stability. Today, therapies based on statins (Libby et al. 2002; Nozue et al. 2012) and other emergent medications (Nicholls et al. 2016) are used by clinicians to enhance plaque stability. However, the effects of all these drugs on the mechanical properties of coronary atherosclerosis lesions still remain unclear. The proposed improved anisotropic elasticity-palpography imaging technique could be used by clinicians to investigate the evolution of the anisotropic mechanical properties of atherosclerotic plaques during drug therapies.

Acknowledgments - Armida Gómez, Jacques Ohayon and Alex EliasZuñiga thank the Mexican Science and Technology Council (CONACYT) and Nuevo-León's Innovation and Technology Transfer Institute (I2 T2). Armida Gómez held a doctoral fellowship from CONACYT (2016-19).

\section{CONFLICT OF INTEREST DISCLOSURE}

The authors have no conflicts of interest to disclose

\section{APPENDIX I. CONSTITUTIVE LAW IN LINEAR ELASTICITY FOR INCOMPRESSIBLE ORTHOTROPIC VASCULAR TISSUES}

The constitutive law is given using the cylindrical coordinate system (R, $\theta, \mathrm{Z})$. In linear elasticity, the relationships between the material constants of a compressible orthotropic medium and the stress tensor $\left(\sigma_{\mathrm{ij}}\right.$ with $\mathrm{i}$, $\mathrm{j}=\mathrm{R}, \theta, \mathrm{Z})$ and strain tensor $\left(\varepsilon_{\mathrm{ij}}\right.$ with $\left.\mathrm{i}, \mathrm{j}=\mathrm{R}, \theta, \mathrm{Z}\right)$ components are given by Berthelot (1999):

$\left\{\begin{array}{c}\varepsilon_{R R} \\ \varepsilon_{\theta \theta} \\ \varepsilon_{Z Z} \\ 2 \varepsilon_{\theta Z} \\ 2 \varepsilon_{R Z} \\ 2 \varepsilon_{R \theta}\end{array}\right\}=\left[\begin{array}{llllll}1 / E_{R} & -v_{\theta R} / E_{\theta} & -v_{Z R} / E_{Z} & 0 & 0 & 0 \\ -v_{R \theta} / E_{R} & 1 / E_{\theta} & -v_{Z \theta} / E_{Z} & 0 & 0 & 0 \\ -v_{R Z} / E_{R} & -v_{\theta Z} / E_{\theta} & 1 / E_{Z} & 0 & 0 & 0 \\ 0 & 0 & 0 & 1 / G_{\theta Z} & 0 & 0 \\ 0 & 0 & 0 & 0 & 1 / G_{R Z} & 0 \\ 0 & 0 & 0 & 0 & 0 & 1 / G_{R \theta}\end{array}\right]\left\{\begin{array}{c}\sigma_{R R} \\ \sigma_{\theta \theta} \\ \sigma_{Z Z} \\ \sigma_{\theta Z} \\ \sigma_{R Z} \\ \sigma_{R \theta}\end{array}\right\}$

where $\mathrm{E}_{\mathrm{i}}(\mathrm{i}=\mathrm{R}, \theta, \mathrm{Z})$ are the three Young's moduli associated with the i directions, $\mathrm{G}_{\mathrm{ij}}=\mathrm{G}_{\mathrm{ji}}(\mathrm{i}, \mathrm{j}=\mathrm{R}, \theta, \mathrm{Z}$ with $\mathrm{i} \neq \mathrm{j}$ ) are the three shear moduli associated with the ij planes, and $\nu_{\mathrm{ij}}=-\varepsilon_{\mathrm{jj} /} / \varepsilon_{\mathrm{ii}}(\mathrm{i}, \mathrm{j}=\mathrm{R}, \theta, \mathrm{Z}$ with $\mathrm{i} \neq \mathrm{j})$ are the six Poisons's ratios (i.e. the ratios of the strain in the $j$ direction to the strain in the perpendicular i direction). Such orthotropic material also obeys to the reciprocity conditions: $v_{\mathrm{ij}} / \mathrm{E}_{\mathrm{i}}=v_{\mathrm{ji}} / \mathrm{E}_{\mathrm{j}}(\mathrm{i}, \mathrm{j}=\mathrm{R}, \theta, \mathrm{Z}$ with $\mathrm{i} \neq \mathrm{j})$. Thanks to these relationships, the number of material constants drops to nine. Moreover, assuming that the vascular wall incompressibility imposes the following three relationships among the Poisson's ratios:

$v_{\mathrm{R} \theta}+v_{\mathrm{RZ}}=0, \quad v_{\theta \mathrm{R}}+v_{\theta \mathrm{Z}}=0 \quad$ and $\quad v_{\mathrm{ZR}}+v_{\mathrm{Z} \theta}=0$.

$$
(\text { AI. } 2 \mathrm{a}-2 \mathrm{c})
$$

So knowing the three Young's moduli $\mathrm{E}_{\mathrm{R}}, \mathrm{E}_{\mathrm{q}}$ and $\mathrm{E}_{\mathrm{Z}}$, we can extract the six Poisson's ratios.

\section{APPENDIX II. THE ELASTIC ANISOTROPY INDEX AI}

Assuming the vascular media as incompressible and under plane strain constraint $\left(\varepsilon_{\mathrm{RZ}}=\varepsilon_{\theta \mathrm{Z}}=\varepsilon_{\mathrm{ZZ}}=0\right)$, one can derive the following relationships (Berthelot 1999):

$\sigma_{R R}(R, \theta)-\sigma_{\theta \theta}(R, \theta)=C(R, \theta) \varepsilon_{R R}(R, \theta)$

with

$C(R, \theta)=E_{R}(R, \theta)\left[1-v_{R Z}(R, \theta) v_{Z R}(R, \theta)\right]^{-1}$

$v_{R Z}(R, \theta)=\frac{1}{2}\left[1-\frac{1}{k_{1}}+\frac{1}{k_{2}}\right]$

$v_{Z R}(R, \theta)=\frac{1}{2}\left[1+k_{2}-\frac{k_{2}}{k_{1}}\right]$ 
$k_{1}=\frac{E_{\theta}(R, \theta)}{E_{R}(R, \theta)}$

(AII.1e)

and

$k_{2}=\frac{E_{Z}(R, \theta)}{E_{R}(R, \theta)}$

where, $\sigma_{R R}(R, \theta), \sigma_{\theta \theta}(R, \theta)$ and $\varepsilon_{R R}(R, \theta)$ are the radial and circumferential stress and radial strain components, respectively.

In this linearized elasticity approach, we assumed that the incremental radial strain $\varepsilon_{R R}(R, \theta)$ is proportional to the imposed change in pressure $\Delta \mathrm{P}$ and inversely proportional to the anisotropic material constant $C(R, \theta)$ :

$\varepsilon_{R R}(R, \theta)=\frac{\Delta P}{C(R, \theta)} g(R, \theta)$

where $g(R, \theta)$ is a correcting shape function, which account for the entire plaque morphology including regions of plaque heterogeneities. By substituting Eq. (AII.2) into Eq. (AII.1a), Eq. (AII.1a) can be rewritten as follow:

$\sigma_{R R}(R, \theta)-\sigma_{\theta \theta}(R, \theta)=\Delta P g(R, \theta)$

Taking advantage of this expression (Eq. (AII.3)), the elastic anisotropy index AI (Eq. (1)) becomes

$A I(\theta)=\frac{\Delta P\left|\int_{R_{i}(\theta)}^{R_{o}(\theta)} g(R, \theta) d R\right|}{\varepsilon(\theta)}$

Since we assumed that the unknown morphological function $g(R, \theta)$ does not depend on the mechanical properties and because this function escapes to direct measurements, we approximated it by a correcting homogeneous shape function $g^{*}(R, \theta)$ accounting only for the anatomical cross-sectional plaque geometry. This approximated correcting function was obtained by performing a FE simulation (with a loading blood pressure differential $\Delta \mathrm{P}$ ) in which the pathologic vessel was assumed homogeneous and made of a quasi-incompressible isotropic material. This approximated shape function $g^{*}(R, \theta)$ was used to estimate the anisotropic palpography index:

$A I(\theta)=\frac{\Delta P\left|\int_{R_{i}(\theta)}^{R_{o}(\theta)} g^{*}(R, \theta) d R\right|}{\varepsilon(\theta)}$

\section{REFERENCES}

Abran M, Cloutier G, Cardinal MH, Chayer B, Tardif JC, Lesage F. Development of a photoacoustic, ultrasound and fluorescence imaging catheter for the study of atherosclerotic plaque. IEEE Trans Biomed Circuits Syst 2014;8:696-703
Ahmadi A, Stone GW, Leipsic J, Serruys PW, Shaw L, Hecht H, Wong G, Nørgaard BL, O'Gara PT, Chandrashekhar Y, Narula J. Association of coronary stenosis and plaque morphology with fractional flow reserve and outcomes. JAMA Cardiol 2016;1:350-357.

Akyildiz AC, Speelman L, Nieuwstadt HA, van Brummelen H, Virmani R, van der Lugt A, van der Steen AFW, Wentzel JJ, Gijsen FJH. The effects of plaque morphology and material properties on peak cap stress in human coronary arteries. Comput Methods Biomech Biomed Eng 2016;19:771-779.

Alsheikh-Ali AA, Kitsios GD, Balk EM, Lau J, Ip S. The vulnerable atherosclerotic plaque: Scope of the literature. Ann Intern Med 2010;153:387-395.

Arbab-Zadeh A, Nakano M, Virmani R, Fuster V. Acute coronary events. Circulation 2012;125:1147-1156.

Baldewsing RA, Schaar JA, Mastik F, van der Steen AFW. Local elasticity imaging of vulnerable atherosclerotic coronary plaques. Adv Cardiol 2007;44:35-61.

Benjamin EJ, Blaha MJ, Chiuve SE, Cushman M, Das SR, Deo R, de Ferranti SD, Floyd J, Fornage M, Gillespie C, Isasi CR, Jiménez MC, Jordan LC, Judd SE, Lackland D, Lichtman JH, Lisabeth L, Liu S, Longenecker CT, Mackey RH, Matsushita K, Mozaffarian D, Mussolino ME, Nasir K, Neumar RW, Palaniappan L, Pandey DK, Thiagarajan RR, Reeves MJ, Ritchey M, Rodriguez CJ, Roth GA, Rosamond WD, Sasson C, Towfighi A, Tsao CW, Turner MB, Virani SS, Voeks JH, Willey JZ, Wilkins JT, Wu JH, Alger HM, Wong SS, Muntner P. American Heart Association Statistics Committee and Stroke Statistics Subcommittee. Heart Disease and Stroke Statistics - 2017 Update: A report from the American Heart Association. Circulation 2017; 135:e146-e603.

Berthelot JM. Elastic behavior of an orthotropic composite. Composite materials. Mechanical Engineering series. New York: Springer; 1999. p. 186-194.

Bonet J, Wood RD. Nonlinear continuum mechanics for finite element analysis. London/New York: Cambridge University Press, 1997.

Bourantas CV, Jaffer FA, Gijsen FJ, Van Soest G, Madden SP, Courtney BK, Fard AM, Tenekecioglu E, Zeng Y, Van Der Steen AFW, Emelianov S, Muller J, Stone PH, Marcu L, Tearney GJ, Serruys PW. Hybrid intravascular imaging: Recent advances, technical considerations, and current applications in the study of plaque pathophysiology. Eur Heart J 2017;38:400-412.

Caplan JD, Waxman S, Nesto RW, Muller JE. Near-infrared spectroscopy for the detection of vulnerable coronary artery plaques. J Am Coll Cardiol 2006;47:C92-C96.

Cardoso L, Kelly-Arnold A, Maldonado N, Laudier D, Weinbaum S. Effect of tissue properties, shape and orientation of microcalcifications on vulnerable cap stability using different hyperelastic constitutive models. J Biomech 2014;47:870-877.

Cardoso L, Weinbaum S. Changing views of the biomechanics of vulnerable plaque rupture: A review. Ann Biomed Eng 2014;42:415431.

Cavalcante JL, Larose E. Intravascular MRI for plaque characterization: Are we close to reality? Curr Cardiol Rep 2016;18:89.

Cespedes I, Ophir J, Ponnekanti H, Maklad N. Elastography: Elasticity imaging using ultrasound with application to muscle and breast in vivo. Ultrason Imaging 1993;15:73-88.

Céspedes EI, De Korte CL, Van Der Steen AFW. Intraluminal ultrasonic palpation: Assessment of local and cross-sectional tissue stiffness. Ultrasound Med Biol 2000;26:385-396.

Chagnon G, Ohayon J, Martiel JL, Favier D. Hyperelasticity modeling for incompressible passive biological tissues. In: Payen Y, Ohayon J, (eds). Biomechanics of living organs. London/San Diego: Elsevier (Academic Press); 2017. p. 3-30.

Cheng JM, Garcia-Garcia HM, De Boer SPM, Kardys I, Heo JH, Akkerhuis KM, Oemrawsingh RM, Van Domburg RT, Ligthart J, Witberg KT, Regar E, Serruys PW, Van Geuns RJ, Boersma E. In vivo detection of high-risk coronary plaques by radiofrequency intravascular ultrasound and cardiovascular outcome: Results of the ATHEROREMO-IVUS study. Eur Heart J 2014;35:639-947.

Chopard R, Boussel L, Motreff p, Rioufol G, Tabib A, Douek P, Meyronet D, Revel D, Finet G. How reliable are $40 \mathrm{MHz}$ IVUS and 64-slice MDCT in characterizing coronary plaque composition? 
An ex vivo study with histopathological comparison. Int J Cardiovasc Imaging 2010;26:373-383.

Cilla M, Peña E, Martínez MA. 3-D computational parametric analysis of eccentric atheroma plaque: Influence of axial and circumferential residual stresses. Biomech Model Mechanobiol 2012;11:10011013.

De Korte CL, Carlier SG, Mastik F, Doyley MM, Van Der Steen AFW, Serruysa PW, Bom N. Morphologic and mechanical information of coronary arteries obtained with intravascular elastography: Feasibility study in vivo. Eur Heart J 2002;23:405-413.

Deleaval F, Bouvier A, Finet G, Cloutier G, Yazdani SK, Le Floc'h S, Clarysse P, Pettigrew RI, Ohayon J. The intravascular ultrasound elasticity-palpography technique revisited: A reliable tool for the in vivo detection of vulnerable coronary atherosclerotic plaques. Ultrasound Med Biol 2013;39:1469-1481.

Di Mario C, Gorge G, Peters R, Kearney P, Pinto F, Hausmann D, von Birgelen C, Colombo A, Mudra H, Roelandt J, Erbel R. Clinical application and image interpretation in intracoronary ultrasound. Study Group on Intracoronary Imaging of the Working Group of Coronary Circulation and of the Subgroup on Intravascular Ultrasound of the Working Group of Echocardiography of the European Society of Cardiology. Eur Heart J 1998;19:207-229.

Doyley MM. Model-based elastography: A survey of approaches to the inverse elasticity problem. Phys Med Biol 2012;57:R35-R73.

Doyley MM, Mastik F, de Korte CL, Carlier SG, Céspedes EI, Serruys PW, Bom N, van der Steen AF. Advancing intravascular ultrasonic palpation toward clinical applications. Ultrasound Med Biol 2001;27:1471-1480

Finet G, Ohayon J, Rioufol G. Biomechanical interaction between cap thickness, lipid core composition and blood pressure in vulnerable coronary plaque: Impact on stability or instability. Coron Artery Dis 2004; 15:13-20.

Fleg JL, Stone GW, Fayad ZA, Granada JF, Hatsukami TS, Kolodgie FD, Ohayon J, Pettigrew R, Sabatine MS, Tearney GJ, Waxman S, Domanski MJ, Srinivas PR, Narula J. Detection of high-risk atherosclerotic plaque: Report of the NHLBI Working Group on current status and future directions. JACC Cardiovasc Imaging 2012;5:941-955.

Fromageau J, Brusseau E, Vray D, Gimenez G, Delachartre P. Characterization of PVA cryogel for intravascular ultrasound elasticity imaging. IEEE Trans Ultrason Ferroelectr Freq Control 2003;50:1318-1324.

Gijsen FJ, Migliavacca F. Plaque mechanics. J Biomech 2014;47:763764

Gijsen FJ, Migliavacca F, Schievano S, Socci L, Petrini L, Thury A, Wentzel JJ, Van Der Steen AFW, Serruys PW, Dubini G. Simulation of stent deployment in a realistic human coronary artery. Biomed Eng Online 2008; 7. Available at: http://www.biomedicalengineering-online.com/content/7/1/23 [cited Mar 6, 2017].

Golemati S, Gastounioti A, Nikita KS. Ultrasound-image-based cardiovascular tissue motion estimation. IEEE Rev Biomed Eng 2016;9:208-218.

Guo X, Zhu J, Maehara A, Monoly D, Samady H, Wang L, Billiar KL, Zheng J, Yang C, Mintz GS. Quantify patient-specific coronary material property and its impact on stress/strain calculations using in vivo IVUS data and 3-D FSI models: A pilot study. Biomech Model Mechanobiol 2017;16:333-344.

Holzapfel GA. Nonlinear solid mechanics: A continuum approach for engineering. New York: Wiley; 2000.

Holzapfel GA, Sommer G, Gasser CT, Regitnig P. Determination of layer-specific mechanical properties of human coronary arteries with nonatherosclerotic intimal thickening and related constitutive modeling. Am J Physiol Circ Physiol 2005;289:H2048-H2058.

Jensen JA, Svendsen NB. Calculation of pressure fields from arbitrarily shaped, apodized, and excited ultrasound transducers. IEEE Trans Ultrason Ferroelectr Freq Control 1992;39:262-267.

Kelly-Arnold A, Maldonado N, Laudier D, Aikawa E, Cardoso L, Weinbaum S. Revised microcalcification hypothesis for fibrous cap rupture in human coronary arteries. Proc Natl Acad Sci USA 2013;110:10741-10746.
Kok AM, Speelman L, Virmani R, Steen AFW, Gijsen FJH, Wentzel JJ. Peak cap stress calculations in coronary atherosclerotic plaques with an incomplete necrotic core geometry. Biomed Eng Online 2016;15:48.

Larose E, Yeghiazarians Y, Libby P, Yucel EK, Aikawa M, Kacher DF, Aikawa E, Kinlay S, Schoen FJ, Selwyn AP, Ganz P. Characterization of human atherosclerotic plaques by intravascular magnetic resonance imaging. Circulation 2005;112:2324-2331.

Le Floc'h S, Ohayon J, Tracqui P, Finet G, Gharib AM, Maurice RL, Cloutier G, Pettigrew RI. Vulnerable atherosclerotic plaque elasticity reconstruction based on a segmentation-driven optimization procedure using strain measurements: Theoretical framework. IEEE Trans Med Imaging 2009;28:1126-1137.

Le Floc'h S, Cloutier G, Finet G, Tracqui p, Pettigrew RI, Ohayon J. On the potential of a new IVUS elasticity modulus imaging approach for detecting vulnerable atherosclerotic coronary plaques: In vitro vessel phantom study. Phys Med Biol 2010;55:5701-5721

Le Floc'h S, Cloutier G, Saijo Y, Finet G, Yazdani SK, Deleaval F, Rioufol G, Pettigrew RI, Ohayon J. A four-criterion selection procedure for atherosclerotic plaque elasticity reconstruction based on in vivo coronary intravascular ultrasound radial strain sequences Ultrasound Med Biol 2012;38:2084-2097.

Lee R, Grodzinsky A, Frank E, Kamm R, Schoen F, Lee RT, Grodzinsky AJ, Frank EH, Kamm RD, Schoen FJ. Structure-dependent dynamic mechanical behavior of fibrous caps from human structure-dependent dynamic mechanical behavior of fibrous caps from human atherosclerotic plaques. Circulation 1991;83:1764-1770.

Libby P, Ridker PM, Maseri A. Inflammation and atherosclerosis. Circulation 2002;105:1135-1143.

Loree HM, Tobias BJ, Gibson LJ, Kamm RD, Small DM, Lee RT Mechanical properties of model atherosclerotic lesion lipid pools. Arterioscler Thromb Vasc Biol 1994;14:230-234.

Madder RD, Husaini M, Davis AT, Vanoosterhout S, Khan M, Wohns D, Mcnamara RF, Wolschleger K, Gribar J, Collins JS, Jacoby M, Decker JM, Hendricks M, Sum ST, Madden S, Ware JH, Muller JE. Large lipid-rich coronary plaques detected by near-infrared spectroscopy at non-stented sites in the target artery identify patients likely to experience future major adverse cardiovascular events. Eur Heart J Cardiovasc Imaging 2016;17:393-399.

Majdouline Y, Ohayon J, Keshavarz-Motamed Z, Roy Cardinal MH, Garcia D, Allard L, Lerouge S, Arsenault F, Soulez G, Cloutier G. Endovascular shear strain elastography for the detection and characterization of the severity of atherosclerotic plaques: In vitro validation and in vivo evaluation. Ultrasound Med Biol 2014;40:890-903.

Maurice RL, Bertrand M. Lagrangian speckle model and tissue-motion estimation-theory [ultrasonography]. IEEE Trans Med Imaging 1999; 18:593-603.

Maurice RL, Ohayon J, Finet G, Cloutier G. Adapting the Lagrangian speckle model estimator for endovascular elastography: Theory and validation with simulated radio-frequency data. J Acoust Soc Am 2004a;116:1276-1286.

Maurice RL, Ohayon J, Frétigny Y, Bertrand M, Soulez G, Cloutier G. Noninvasive vascular elastography: Theoretical framework. IEEE Trans Med Imaging 2004b;23:164-180.

Maurice RL, Fromageau J, É Brusseau, Finet G, Rioufol G, Cloutier G. On the potential of the Lagrangian estimator for endovascular ultrasound elastography: In vivo human coronary artery study. Ultrasound Med Biol 2007;33:1199-1205.

Morbiducci U, Kok AM, Kwak BR, Stone PH, Steinman DA, Wentzel JJ. Atherosclerosis at arterial bifurcations: Evidence for the role of haemodynamics and geometry. Thromb Haemost 2016;115:484 492.

Naghavi M, Libby P, Falk E, Casscells SW, Litovsky S, Rumberger J, Badimon JJ, Stefanadis C, Moreno P, Pasterkamp G, Fayad Z, Stone PH, Waxman S, Raggi P, Madjid M, Zarrabi A, Burke A, Yuan C, Fitzgerald PJ, Siscovick DS, de Korte CL, Aikawa M, Juhani Airaksinen KE, Assmann G, Becker CR, Chesebro JH, Farb A, Galis ZS, Jackson C, Jang IK, Koenig W, Lodder RA, March K, Demirovic J, Navab M, Priori SG, Rekhter MD, Bahr R, Grundy SM, Mehran R, Colombo A, Boerwinkle E, Ballantyne C, Insull W, 
Schwartz RS, Vogel R, Serruys PW, Hansson GK, Faxon DP, Kaul S, Drexler H, Greenland P, Muller JE, Virmani R, Ridker PM, Zipes DP, Shah PK, Willerson JT. From vulnerable plaque to vulnerable patient: A call for new definitions and risk assessment strategies: Part I. Circulation 2003;108:1664-1672.

Nayak R, Huntzicker S, Ohayon J, Carson N, Dogra V, Schifitto G, Doyley MM. Principal strain vascular elastography: Simulation and preliminary clinical evaluation. Ultrasound Med Biol 2017;43:682699.

Nicholls SJ, Puri R, Anderson T, Ballantyne CM, Cho L, Kastelein JJP, Koenig W, Somaratne R, Kassahun H, Yang J, Wasserman SM, Scott R, Ungi I, Podolec J, Ophuis AO, Cornel JH, Borgman M, Brennan DM, Nissen SE. Effect of evolocumab on progression of coronary disease in statin-treated patients. JAMA 2016;316:2373.

Nozue T, Yamamoto S, Tohyama S, Umezawa S, Kunishima T, Sato A, Miyake S, Takeyama Y, Morino Y, Yamauchi T, Muramatsu T, Hibi K, Sozu T, Terashima M, Michishita I. Statin treatment for coronary artery plaque composition based on intravascular ultrasound radiofrequency data analysis. Am Heart J 2012;163:191-199.

Ohayon J, Dubreuil O, Tracqui P, Le Floc'h S, Rioufol G, Chalabreysse L, Thivolet F, Pettigrew RI, Finet G. Influence of residual stress/ strain on the biomechanical stability of vulnerable coronary plaquesp: otential impact for evaluating the risk of plaque rupture. Am J Physiol Hear Circ Physiol 2007;293:1987-1996.

Ohayon J, Finet G, Gharib AM, Herzka DA, Tracqui P, Heroux J, Rioufol G, Kotys MS, Elagha A, Pettigrew RI. Necrotic core thickness and positive arterial remodeling index: Emergent biomechanical factors for evaluating the risk of plaque rupture. Am J Physiol Heart Circ 2008;295:H717-H727.

Ohayon J, Finet G, Le Floc'h S, Cloutier G, Gharib AM, Heroux J, Pettigrew RI. Biomechanics of atherosclerotic coronary plaque: Site, stability and in vivo elasticity modeling. Ann Biomed Eng 2014;42:269-279.

Ophir J, Céspedes I, Ponnekanti H, Yazdi Y, Li X. Elastography: A quantitative method for imaging the elasticity of biological tissues. Ultrason Imaging 1991;13:111-134.

Poree J, Chayer B, Soulez G, Ohayon J, Cloutier G. Noninvasive vascular modulography method for imaging the local elasticity of atherosclerotic plaques: Simulation and in vitro vessel phantom study. IEEE Trans Ultrason Ferroelectr Freq Control 2017;64:1805-1817.
Richards MS, Doyley MM. Investigating the impact of spatial priors on the performance of model-based IVUS elastography. Phys Med Biol 2011;56:7223-46.

Richards MS, Perucchio R, Doyley MM. Visualizing the stress distribution within vascular tissues using intravascular ultrasound elastography: A preliminary investigation. Ultrasound Med Biol 2015;41:1616-1631.

Rioufol G, Finet G, Ginon I, André-Fouët X, Rossi R, Vialle E, Desjoyaux E, Convert G, Huret JF, Tabib A. Multiple atherosclerotic plaque rupture in acute coronary syndrome: A three-vessel intravascular ultrasound study. Circulation 2002;106:804-808.

Schaar JA, De Korte CL, Mastik F, Van Damme LCA, Krams R, Serruys PW, Van Der Steen AFW. Three-dimensional palpography of human coronary arteries: Ex vivo validation and in-patient evaluation. Herz 2005;30:125-133.

Sinclair H, Bourantas C, Bagnall A, Mintz GS, Kunadian V. OCT for the identification of vulnerable plaque in acute coronary syndrome. JACC Cardiovasc Imaging 2015;8:198-209.

Soleimanifard S, Abd-Elmoniem KZ, Agarwal HK, Tomas MS, Sasano T, Vonken E, Youssef A, Abraham MR, Abraham TP, Prince JL. Identification of myocardial infarction using three-dimensional strain tensor fractional anisotropy. Proc IEEE Int Symp Biomed Imaging 2010;2010:468-471.

Tacheau A, Le Floc'h S, Finet G, Doyley MM, Pettigrew RI, Cloutier $\mathrm{G}$, Ohayon J. The imaging modulography technique revisited for high-definition intravascular ultrasound: Theoretical framework. Ultrasound Med Biol 2016;42:727-741.

Tang D, Teng Z, Canton G, Hatsukami TS, Dong L, Huang X, Yuan C. Local critical stress correlates better than global maximum stress with plaque morphologic features linked to atherosclerotic plaque vulnerability: An in vivo multi-patient study. Biomed Eng Online 2009;8:15.

Thondapu V, Bourantas CV, Foin N, Jang IK, Serruys PW, Barlis P. Basic science for the clinician: Biomechanical stress in coronary atherosclerosis: Emerging insights from computational modelling. Eur Heart J 2017;38:81-92.

Widynski N, Porée J, Roy Cardinal MH, Ohayon J, Cloutier G, Garcia D. A sequential Bayesian based method for tracking and strain palpography estimation of arteries in intravascular ultrasound images. Proc IEEE Int Ultrason Symp 2014;515-518. 